\title{
Which factors predict cognitive decline in Parkinson's disease?
}

Dominique Caparros-Lefebvre, Nathalie Pécheux, Violaine Petit, Alain Duhamel, Henri Petit

\begin{abstract}
The study assessed cognitive decline in non-demented, non-depressed patients with well defined Parkinson's disease and determined the predictive value for cognitive decline of different motor symptoms. Motor disability was measured with the Unified Parkinson's disease rating scale, impairment in activities of daily living, levodopa test, and long term clinical follow up. Neuropsychological evaluations included modified mini mental state, fluency, Wechsler logical memory, Wisconsin card sorting test, and the Montgomery and Asberg depression rating scale. Fifty three patients fulfilling clinical criteria for idiopathic Parkinson's disease were studied. Cognitive performance on initial testing was significantly correlated with education and disease duration but not with age at disease onset. Cognitive performance on retesting after three years of follow up was significantly reduced. This reduction was significantly greater in the late onset group, in patients with isolated dystonic dyskinesiae, and in patients with a lower percentage of motor improvement on levodopa. Cognitive decline in idiopathic Parkinson's disease may depend on both the prevalence of non-dopaminergic lesions and the topography of dopaminergic denervation. Predictive factors for cognitive decline, especially in executive tasks, relate more to non-dopaminergic than to dopaminergic lesions.
\end{abstract}

$(尹$ Neurol Neurosurg Psychiatry 1995;58:51-55)

Department of Neurology, CHU Lille, France

D Caparros-Lefebvre

N Pécheux

V Petit

H Petit

Department of Information Science, CHU Lille, France A Duhamel

Correspondence to: Dr D Caparros-Lefebvre, Department of Neurology, Hopital B, CHU Lille, F59037 Lille Cedex, France.

Received 25 August 1993 and in final revised form 31 May 1994.

Accepted for publication

6 June 1994
Keywords: Parkinson's disease; cognitive decline; motor symptoms

Cognitive decline in Parkinson's disease has been clearly reported in the medical literature. ${ }^{1}$ Initially, most studies employed a cross sectional approach using different tests in unselected groups of patients. ${ }^{23}$ Later, other studies dissected specific patterns of cognitive deficits such as visuospatial and temporal ordering impairment or frontal type deficit. ${ }^{4-7}$ The relation between motor and cognitive disorders in Parkinson's disease is controversial, including opposing effects of medication on motor control and cognitive function. A positive association between bradykinesia and visuospatial deficit has been noted, ${ }^{8}$ yet a clear dissociation between cognition and motor control has been shown in early untreated Parkinson's disease. ${ }^{9}$ Most workers consider that longitudinal studies are necessary to determine whether increasing duration of disease exacerbates early cognitive deficits and affects new cognitive domains. The predictive value of motor symptoms for cognitive decline remains controversial. ${ }^{3-11}$ In the same way, the degree and rate of cognitive decline have not been evaluated in different subgroups of patients with levodopa induced dyskinesiaenamely, those with choreic, dystonic, or mixed dyskinesiae. The dyskinesiae themselves have been extensively described. ${ }^{12} 13$ Peak dose choreic dyskinesiae, which usually occur in young patients with good response to levodopa, ${ }^{14}$ are thought to be related to hypersensitivity of dopaminergic receptors, ${ }^{15}$ and probably reflect a large predominance of dopaminergic lesions in idiopathic Parkinson's disease. Dystonic dyskinesiae in Parkinson's disease occur during off periods or at the onset and the end of improvement in parkinsonian disability ${ }^{12}$ but are also a common feature of multiple system atrophy and progressive supranuclear palsy, ${ }^{16}$ and might involve both dopaminergic and non-dopaminergic systems. We selected 60 non-demented, non-depressed patients with idiopathic Parkinson's disease. Patients with unequivocal dementia were excluded. This choice was based on major conclusions from the literature: (1) by contrast with earlier estimates, the prevalence of dementia in Parkinson's disease does not occur in more than 10 to $15 \%$ of patients. ${ }^{1}{ }^{17} 18$ (2) Although dementia therefore seems to be infrequent, minor cognitive disorders have been clearly shown to occur in most patients, ${ }^{7}$ including early untreated patients. ${ }^{10}$ In non-demented patients, previous studies have shown isolated deficits in long term memory, visuospatial tasks, and frontal lobe function ${ }^{568}$ whereas most studies that have compared Parkinson's disease dementia with Alzheimer's disease have failed to show any quantitative difference in learning new information. ${ }^{19}$ This may suggest that the common minor cognitive deficit in Parkinson's disease and the relatively uncommon dementia of Parkinson's disease do not depend on the same causal factors, or on the same predictive risk factors. Dementia in Parkinson's disease could also be triggered by associated disorders such as stroke or cortical degeneration of 
Table 1 Patient characteristics

\begin{tabular}{|c|c|c|c|c|c|c|c|c|c|}
\hline & No & $\begin{array}{l}\text { Years of } \\
\text { education }\end{array}$ & $\begin{array}{l}\text { Age } 1 \\
(y)\end{array}$ & $\begin{array}{l}\text { Age } 2 \\
(y)\end{array}$ & $\begin{array}{l}\text { Test } 1 \text {-test2 } \\
\text { interval } \\
\text { (months) }\end{array}$ & $\begin{array}{l}\text { Improvement } \\
\text { on } \\
\text { levodopa } \\
(\%)\end{array}$ & $\begin{array}{l}\text { Levodopa } \\
\text { (mg/day) }\end{array}$ & UPDRS & $\% A D L$ \\
\hline $\begin{array}{l}\text { Group } \\
\text { 1st symptom: }\end{array}$ & 53 & $9 \cdot 6(3)$ & $61 \cdot 7(9)$ & $64.8(9)$ & $37(4)$ & $54.9(9)$ & $462(178)$ & $38(13)$ & $71(15)$ \\
\hline $\begin{array}{l}\text { Akinesia } \\
\text { Tremor } \\
\text { Type of dyskinesia: }\end{array}$ & $\begin{array}{l}19 \\
34\end{array}$ & $\begin{array}{c}10(4) \\
9 \cdot 3(2)\end{array}$ & $\begin{array}{l}59 \cdot 7(7) \\
62 \cdot 8(9)\end{array}$ & $\begin{array}{l}62 \cdot 8(7) \\
65.9(9)\end{array}$ & $\begin{array}{l}37(4) \\
37(4)\end{array}$ & $\begin{array}{l}57.6(11) \\
53.4(9)\end{array}$ & $\begin{array}{l}494(175) \\
444(180)\end{array}$ & $\begin{array}{l}38(15) \\
38(11)\end{array}$ & $\begin{array}{l}72(15) \\
71(15)\end{array}$ \\
\hline $\begin{array}{l}\text { Choreic } \\
\text { Dystonic } \\
\text { Mixed }\end{array}$ & $\begin{array}{l}16 \\
18 \\
19\end{array}$ & $\begin{aligned} 9 \cdot 4(3) \\
10 \cdot 7(4) \\
8 \cdot 7(1 \cdot 5)\end{aligned}$ & $\begin{array}{l}62(6) \\
63 \cdot 7(10) \\
59 \cdot 4(9)\end{array}$ & $\begin{array}{l}65(6) \\
66 \cdot 9(10) \\
62 \cdot 4(9)\end{array}$ & $\begin{array}{l}37(4) \\
38(4) \\
36(4)\end{array}$ & $\begin{array}{l}54 \cdot 7(8) \\
52 \cdot 2(9) \\
57 \cdot 6(11)\end{array}$ & $\begin{array}{l}540(120) \\
391(140) \\
463(226)\end{array}$ & $\begin{array}{l}39(10) \\
33(12) \\
41(15)\end{array}$ & $\begin{array}{l}69(14) \\
77(14) \\
67(15)\end{array}$ \\
\hline
\end{tabular}

Age 1 = age at the first evaluation; age $2=$ age at the second evaluation; UPDRS $=$ unified Parkinson's disease rating scale; $\mathrm{ADL}=$ activities of daily living.

Alzheimer's disease type. ${ }^{20}$ These associated factors could carry a patient with Parkinson's disease across the threshold for the appearance of clinical dementia.

Patients have been evaluated twice, with a three year interval, with the same tests. These are simple and well known tests and have been reported to be sensitive to either memory impairment (Wechsler memory scale ${ }^{21}$ ) or frontal lobe damage (Wisconsin card sorting test (WSCT) ${ }^{22}$ ). The aims of the study were to define: (a) the predictive value for cognitive decline of the initial symptoms of the disease, (b) the influence on cognitive decline of demographic factors (education level, age at onset, disease duration), and (c) the role of motor state (unified Parkinson's disease rating scale (UPDRS) score and activities of daily living (ADL) score, levodopa daily dose, percentage of improvement after levodopa, and type of dyskinesia).

\section{Patients and methods \\ PATIENTS}

Sixty patients enrolled between September 1987 and March 1989 were selected on the basis of a diagnosis of idiopathic Parkinson's disease, according to published diagnostic criteria. ${ }^{23}$ Exclusion criteria included severe head injury, stroke, previous exposure to neuroleptics, history of thyroid disease or diabetes, poor response to levodopa (less than 35\% improvement), minor or major depression (Montgomery and Asberg depression rating scale $($ MADRS $)>20)$, and dementia (according to DSM III-R criteria ${ }^{24}$ ). No patient had undergone any neurosurgical operation. Patients were self declared as right handed except three who were left handed. All patients were re-evaluated with the same tests three years after the first (the mean interval between tests was 37 (range 30-46) months, similar in each subgroup). Seven patients were excluded after the second evaluation because of the occurrence of depression, cerebrovascular disorder, or severe reduction of responsiveness to levodopa. This report therefore analyses the results of the 53 patients who fulfilled the inclusion criteria both at the first evaluation and also at follow up (table 1).

\section{PROCEDURE}

The motor and neuropsychological evaluations were carried out at the same time. A neurologist administered the UPDRS, ${ }^{25}$ a quantitative measure of motor disability, including akinesia, tremor, rigidity, postural instability, and walking. Impairment in $\mathrm{ADL}^{26}$ was assessed ( $0 \%$ to $100 \%$ of self sufficiency). The response to levodopa and the type of dyskinesia (peak-dose choreic dyskinesia, onset and end of dose dyskinesia, or early morning dystonia, and association of more than one type) ${ }^{12}$ was evaluated by a previous levodopa test ${ }^{13}$ and by long term clinical follow up (most patients were followed up every six to nine months by the same neurologist from the onset of disease to the final evaluation). Reduction in performance was assessed in subgroups of patients according to clinical criteria. The two main clinical criteria were (1) the type of symptom at onset: akinesia or tremor, and (2) the type of levodopa induced dyskinesia: choreic, dystonic, or mixed (table 2). Other clinical criteria included age of onset of disease (three groups: $<50$ years $(n=17), 50$ to 60 years $(n=27),>60$ years $(\mathbf{n}=9)), \%$ of improvement after levodopa (two groups: 35 to $50 \%(n=30),>50 \%(n=$ 23)), daily levodopa dose (plus PDI) (three

Table 2 Performance on tests 1 and decline after three years

\begin{tabular}{|c|c|c|c|c|c|c|c|c|c|c|c|c|}
\hline & No & $\begin{array}{l}\text { Age at } \\
\text { onset (y) }\end{array}$ & $\begin{array}{l}\text { Disease } \\
\text { duration }(y)\end{array}$ & $\underset{(157)}{\operatorname{mMMS1}}$ & $d m M M S$ & Flu 1 & $d F l u$ & $\begin{array}{l}\text { Mem1 } \\
(/ 23)\end{array}$ & $d M e m$ & $\begin{array}{l}\text { WISC } \\
\text { Pers }\end{array}$ & $\begin{array}{l}\text { WISC } \\
\text { dPers }\end{array}$ & $\begin{array}{l}\text { WISC1 } \\
\text { Err }\end{array}$ \\
\hline \multirow{2}{*}{$\begin{array}{l}\text { Group } \\
\text { 1st symptom: } \\
\text { Akinesia } \\
\text { Tremor }\end{array}$} & 53 & $53(8)$ & $8 \cdot 6(5 \cdot 3)$ & $51 \cdot 4(4)$ & $-1 \cdot 38(2)^{\star \star \star \star}$ & $17 \cdot 4(5)$ & $-1 \cdot 4(3)^{\star \star \star}$ & $9 \cdot 4(4 \cdot 4)$ & $-1 \cdot 5(3)^{\star \star \star}$ & $3 \cdot 2(3)$ & $+2.9(9)^{\star}$ & $6.5(5)$ \\
\hline & $\begin{array}{l}19 \\
34\end{array}$ & $\begin{array}{l}50 \cdot 9(6) \\
54 \cdot 2(9)\end{array}$ & $\begin{array}{l}8 \cdot 7(5 \cdot 6) \\
8 \cdot 6(5 \cdot 3)\end{array}$ & $\begin{array}{l}51 \cdot 9(7 \cdot 6) \\
51 \quad(3 \cdot 5)\end{array}$ & $\begin{array}{ll}-1.5 & (1 \cdot 6)^{\star} \\
-1 \cdot 3 & (2 \cdot 3)^{\star \star}\end{array}$ & $\begin{array}{l}17 \cdot 1(4) \\
17 \cdot 6(6)\end{array}$ & $\begin{array}{l}-1 \cdot 5(3)^{\star \star} \\
-1 \cdot 3(3)^{\star \star}\end{array}$ & $\begin{array}{l}9 \cdot 6(5) \\
9 \cdot 3(4)\end{array}$ & $\begin{array}{l}-2 \cdot 3(3 \cdot 6)^{\star} \\
-1(3)^{\star}\end{array}$ & $\begin{array}{l}2.8(3) \\
3.4(3)\end{array}$ & $\begin{array}{l}+4 \cdot 1(9 \cdot 5)^{\star} \\
+2 \cdot 3(8)^{\star}\end{array}$ & $\begin{array}{l}5.9(5.6) \\
6.8(5.6)\end{array}$ \\
\hline \multicolumn{13}{|c|}{ Type of dyskinesia: } \\
\hline $\begin{array}{l}\text { Choreic } \\
\text { Dystonic } \\
\text { Mixed }\end{array}$ & $\begin{array}{l}16 \\
18 \\
19\end{array}$ & $\begin{array}{l}52 \cdot 5(5) \\
57 \cdot 3(9 \cdot 3) \\
49 \cdot 5(6 \cdot 7)\end{array}$ & $\begin{array}{l}9 \cdot 5(4) \\
6.5(4 \cdot 4) \\
9.9(6.4)\end{array}$ & $\begin{array}{l}51.4(4) \\
52.9(3) \\
49.9(4)\end{array}$ & $\begin{array}{l}-1 \cdot 5(2)^{\star \star} \\
-2 \cdot 2(2 \cdot 4)^{\star \star \star} \\
-0.5(1.5)\end{array}$ & $\begin{array}{l}16.9(5) \\
18 \cdot 4(5) \\
16.9(6)\end{array}$ & $\begin{array}{l}-1 \cdot 4(3)^{\star \star} \\
-1 \cdot 7(3)^{\star \star} \\
-1 \cdot 2(2 \cdot 5)^{\star \star}\end{array}$ & $\begin{array}{l}9 \cdot 3(4 \cdot 3) \\
10 \cdot 7(3 \cdot 6) \\
8 \cdot 2(5)\end{array}$ & $\begin{array}{l}-1(3 \cdot 3)^{\star} \\
-2 \cdot 2(4)^{\star} \\
-1 \cdot 2(2 \cdot 4)^{\star}\end{array}$ & $\begin{array}{l}2 \cdot 9(2 \cdot 4) \\
2 \cdot 6 \\
4 \cdot 1(4)\end{array}$ & $\begin{array}{l}+3.1(8)^{\star} \\
+3.8(2 \cdot 7)^{\star} \\
+1.9(7)^{\star}\end{array}$ & $\begin{array}{l}6 \cdot 4(5 \cdot 6) \\
5 \cdot 6(10) \\
7 \cdot 5(6)\end{array}$ \\
\hline
\end{tabular}

Tests 1 performance on each subtest (modified mini mental state (mMMS), fluency (Flu), logical memory (Mem), Wisconsin card sorting tests (Pers, Err, time), and Montgomery and Asberg depression rating scale (MADRS), and performance decline (d) to tests 2 .

Montgomery and Asberg depression rating scale (MADRS) 
Modified mini mental state (mMMS) decline in subgroups divided according to the type of dyskinesia. 1 = dystonic subgroup; 2 = choreic subgroup; 3 = subgroup with mixed dyskinesiae; $\star p<0.02$.

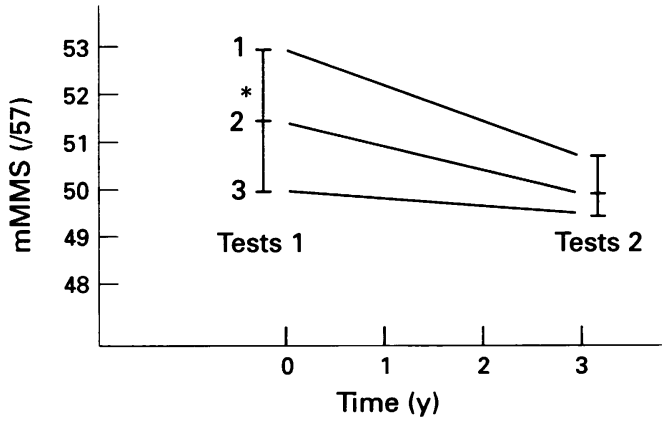

groups: $<350 \mathrm{mg}(\mathrm{n}=16), 350$ to $550 \mathrm{mg}$ (n $=24)$, and $>550 \mathrm{mg}(\mathrm{n}=13)$ ), UPDRS score (three groups: $<30(n=14), 30-44$ (n $=28),>44(n=11)), \%$ ADL (three groups: $<60 \%(n=8), 60-80 \%(n=19),>80 \%$ ( $n$ $=26)$ ). Change in depression was assessed according to the $\mathrm{MADRS}^{27}$ at the end of each neuropsychological evaluation (dMADRS = MADRS1 - MADRS2). A global measure of cognitive status was obtained with the modified mini mental state examination ${ }^{128}$ $(\mathrm{dmMMS}=\mathrm{mMMS} 1-\mathrm{mMMS} 2)$. The specific memory evaluation comprised the logical memory subtest of the Wechsler memory scale, ${ }^{21}$ with immediate recall (dMem $=$ Mem1 - Mem2). The frontal lobe tasks comprised semantic fluency (animals) $(\mathrm{dFlu}=$ Flu1 - Flu2) and the Wisconsin card sorting test (WSCT) ${ }^{22}$ with six categories to be defined (dCateg = Categ1 - Categ2) and measures of perseveration (dPers $=$ Pers 1 Pers2), total errors $(\mathrm{dErr}=\mathrm{Err} 1-\mathrm{Err} 2)$, and time $($ dtime $=$ time $1-$ time 2$)$.

\section{STATISTICAL ANALYSIS}

Statistical analysis was performed with SAS. ${ }^{29}$ For variables distributed according to the Laplace-Gauss law, differences between data sets were evaluated by one way and repeated measures analyses of variance (ANOVA). Planned comparisons between sets of data were made with Kruskall-Wallis tests when variables were not normally distributed. Correlations between continuous variables were determined with Pearson's productmoment correlation coefficient $r$.

\section{Results}

MOTOR EVALUATION

Patients divided according to the initial symptom (akinesia $v$ tremor) did not differ in

\begin{tabular}{llccl}
\hline $\begin{array}{l}\text { WISC } \\
d E r r\end{array}$ & $\begin{array}{l}\text { WISC1 } \\
\text { time }\end{array}$ & $\begin{array}{l}\text { WISC } \\
\text { dtime }\end{array}$ & $\begin{array}{l}\text { MADRS1 } \\
(160)\end{array}$ & $d M A D R S$ \\
\hline$+3 \cdot 1(8)^{\star \star}$ & $277(165)$ & $99(238)^{\star}$ & $7 \cdot 9(5)$ & $1 \cdot 2(5)$ \\
$+4 \cdot 4(9 \cdot 6)^{\star \star}$ & $262(164)$ & $159(280)^{\star \star}$ & $7 \cdot 2(6 \cdot 6)$ & $2 \cdot 3(6 \cdot 6)$ \\
$+2 \cdot 4(7 \cdot 7)^{\star \star}$ & $285(167)$ & $65(208)^{\star \star}$ & $8 \cdot 2(3 \cdot 7)$ & $0.6(4)$ \\
& & & & \\
$+2 \cdot 3(7 \cdot 6)^{\star}$ & $302(158)$ & $80(261)^{\star \star}$ & $10 \cdot 2(6 \cdot 8)$ & $0 \cdot 4(6)$ \\
$+4 \cdot 3(5 \cdot 7)^{\star}$ & $200(110)$ & $154(275)^{\star \star}$ & $6 \cdot 3(3 \cdot 7)$ & $1 \cdot 7(4)$ \\
$+2 \cdot 7(6 \cdot 6)^{\star}$ & $328(193)$ & $62(175)^{\star}$ & $7 \cdot 5(3)$ & $2(5 \cdot 3)$ \\
\hline
\end{tabular}

age at onset, disease duration, education, daily levodopa dose, UPDRS, and \% ADL. Percentage of improvement after levodopa was slightly higher in the akinetic group. Patients divided according to their type of dyskinesia did not differ in education, or age, but disease duration, percentage of improvement after levodopa and daily levodopa dose were lower in the dystonic subgroup.

TESTS 1

In the group as a whole ( $n=53), \mathrm{mMMS}$ and fluency were negatively correlated with disease duration (respectively, $r=-0.41, p<$ 0.01 and $r=-0.36, \mathrm{p}<0.01)$. The WCST Pers and time were positively correlated with disease duration (respectively, $r=0.29, \mathrm{p}<$ 0.05 and $r=0.29, \mathrm{p}<0.01$ ). Performance on tests 1 was not correlated with the age at disease onset, or with the age 1 . Results on all tests except fluency were strongly correlated with education (mMMS1: $r=0.47, \mathrm{p}<$ 0.001 ; Flu1: $r=0.23, p=0.10 ; \quad$ Mem1: $r=0.36, \mathrm{p}<0.01$; Pers 1: $r=-0.38, \mathrm{p}<$ 0.01; Err1: $r=-0.42, \mathrm{p}<0.002$; Time1: $r=-0.39, \quad \mathrm{p}<0.01)$. Patients divided according to the initial symptom (akinesia $v$ tremor) did not differ in performance on tests 1 , but results on all tests except fluency were slightly higher in the akinetic group. Patients divided according to the type of dyskinesia differed significantly in results on mMMS1 ( $<<0.02$; table 2). Planned between group comparisons showed that results on tests 1 differed significantly according to $\mathrm{ADL}$ score, performance being lower in groups with lower ADL $(p<0.05)$. Patients divided according to their UPDRS score were significantly different only for fluency. Tests 1 did not differ according to percentage of improvement after levodopa or to daily levodopa dose.

TESTS 2 AND THE DECLINE BETWEEN TESTS 1 AND 2 (DTESTS)

The MADRS2 did not differ significantly from MADRS1. For the whole group, the second evaluation showed significantly inferior performance on all tests both in memory and frontal function (table 2). Performance reduction on tests 2 was not correlated with education and did not depend on the age at the second evaluation (age 2). Performance reduction on WCST was significantly greater in patients with late disease onset ( $>60$ years; $p<0.05$ ), whereas the two other groups did not differ $(<50$ years: dcateg $=-1, \quad$ dPers $=+3, \quad$ dErr $=+3$; 50-60: dcateg $=-0 \cdot 22$, dPers $=+0 \cdot 88$, dErr $=+1 \cdot 44,>60$ : dcateg $=-1 \cdot 88$, dPers $=+$ $8 \cdot 4$, dErr $=+9$ ). Performance reduction was significant in subgroups divided according to the initial symptom. Akinetic patients worsened slightly more than tremulous patients on all tests, but not significantly (table 2). The mMMS decrease (dmMMS) (fig 1) and WCST dtime $(p<0.01)$ were significantly greater in the subgroup with dystonic dyskinesiae. Performance reduction on other tests was also greater for the dystonic group, but 
not significantly so. Performance reduction on WCST (Pers and Err) was significantly greater in patients with a lower \% of improvement after levodopa (35-50\%: dPers $=4.9$, $\mathrm{dErr}=5 \cdot 2,>50 \%: \mathrm{dPers}=0.3, \mathrm{dErr}=0.4$; p < 0.05). Tests 2 and dtests did not differ according to daily levodopa dose. Fluency 2 was significantly lower in groups with higher UPDRS $(p<0.02)$ (UPDRS $<30$, Flu $2=$ 20; UPDRS: $30-44$, Flu $2=15$; UPDRS $>$ 44, Flu2 = 12). Performance on tests 2 was significantly lower $(p<0.01)$ in groups with lower $\mathrm{ADL}(\mathrm{ADL}>80 \%, \mathrm{mMMS} 2=52$, Flu2 $=19$, Mem2 = 10, Pers2 = 2.6, Err2 = 5.4, Time $2=265$; ADL: $60-80, \mathrm{mMM} 2=$ 48, Flu2 $=13$, Mem $2=6$, Pers $2=10$, Err2 $=14$, Time $2=496 ; \mathrm{ADL}<60 \%, \mathrm{mMM} 2=$ 48, Flu2 $=12$, Mem2 $=7$, Pers $2=7 \cdot 5$, Err2 $=13$, Time $2=446$ ).

\section{Discussion}

The aim of this study was to define the cognitive decline in different subgroups of nondemented patients with Parkinson's disease. The study also included only non-depressed patients. The MADRS 1 was low and MADRS 2 was not significantly different in all subgroups. The lack of depression at the first evaluation and during the follow up was necessary for the validity of the study of isolated cognitive decline.

Performance on tests 1 did not depend on age of onset of disease, or age when the evaluation was performed but instead correlated with disease duration, and performance decline did not depend on age 2 . This suggests that despite previous reports, the degenerative process, unlike aging, has a prominent role in cognitive decline. ${ }^{30}$ Both duration of disease and degree of motor impairment had been considered as risk factors for cognitive decline. ${ }^{131}$ Of these two, duration of disease could be more reliable and less subjective because the large number of Parkinson's disease motor disability rating scales used makes meta-analysis difficult. Performance reduction on WCST was greater in the late onset subgroup, in keeping with the results of other studies. ${ }^{3233}$ Except for fluency, the results on tests 1 were strongly correlated with years of education. Mayeux et al ${ }^{1}$ have shown that education significantly influences mMMS performance and the role of education has also been emphasised in the study of risk factors for dementia of Alzheimer's disease type. ${ }^{34}$ Thus the threshold of appearance of cognitive deficit may be reached earlier in patients with lower education level, both in Parkinson's disease and Alzheimer's disease. Our results, however, did not show an effect of education on the rapidity of cognitive decline.

The three-year follow up of the whole group provided evidence of progressive cognitive decline, both in memory and executive functions, irrespective of duration of disease. Interestingly, performances on all tests were reduced by the same degree at the second evaluation. Both subcortical and cortical lesions have been described in demented patients with
Parkinson's disease, ${ }^{35}{ }^{36}$ but the relation between lesion topography and subtypes of cognitive impairment is unclear..$^{710}$

The predictive value of initial motor symptoms for subsequent cognitive decline remains controversial. Our results indicate only a trend for decline in performance on all tests to be greater in the akinetic than in the tremulous subgroup. The respective role of dopaminergic and non-dopaminergic lesions in relation to cognitive deficits in Parkinson's disease has been widely debated, ${ }^{71035}$ and a poor response to levodopa and the presumed presence of non-dopaminergic lesions have been considered as good risk factors for dementia. ${ }^{10}$ The effect of levodopa is often greater on akinesia than on tremor, which might suggest that akinesia is more related to predominant dopaminergic, and tremor to non-dopaminergic lesions. It therefore seems paradoxical that tremor is associated with better cognitive prognosis. The exact pathophysiology, however, of parkinsonian tremor remains unknown, and dysfunction outside basal ganglia (for example, in the cerebellum) may underlie its occurrence. The possibility that type of dyskinesia might influence cognitive decline has not previously been examined. In our patients, results on tests 1 were better in the dystonic subgroup, which might be explained by shorter duration of disease. By contrast, cognitive decline was more severe in the same subgroup. Choreic peak dose dyskinesiae usually occur in patients with a good response to levodopa, unlike dystonic dyskinesiae, which tend to occur in both Parkinson's disease and in other diseases causing parkinsonism such as multiple system atrophy and progressive supranuclear palsy. The first may be an index of predominant dopaminergic lesions. It has been suggested that different nigral inputs to the striatum may be involved in the occurrence of either choreic or dystonic dyskinesiae. ${ }^{37}$ Also, experimental studies have shown that thalamic stimulation improves choreic, but not dystonic dyskinesiae, suggesting that they may be mediated by different striatal inputs projecting separately to distinct thalamic nuclei. ${ }^{38}$ It has been hypothesised that dystonic dyskinesiae might be related to predominant denervation in the dorsal striatum, and choreic dyskinesiae to moderate denervation in the ventral striatum. ${ }^{37}$ Hence, it is conceivable that differential denervation in patients with different types of dyskinesia might have different consequences on cognitive functions. In patients with higher $\%$ of improvement on levodopa, probably the best correlate of the nigrostriatal dopaminergic lesions in Parkinson's disease, ${ }^{1213}$ performances on WCST 2 (Pers 2 and Err 2) were unchanged. By contrast, patients with lower \% of improvement showed increasing difficulties in frontal lobe function, which confirms that the cortical lesions, predominating in the prefrontal region in parkinsonian patients, involved non-dopaminergic pathways.

Our study shows that clinical features classified according to their presumed relation with dopaminergic lesions-choreic and mixed 
dyskinesiae, high \% of improvement, and high ADL score-are associated with a lower risk for cognitive decline. Late onset of disease, low improvement with levodopa, and dystonic dyskinesiae are risk factors for decline in cognitive, and especially in frontal lobe, function.

We are grateful to Dr B Pillon who reviewed the manuscript and gave his valuable comments. We thank $F$ Dehier for her help in the statistical analysis, which was performed at the Service d'Etudes et de Recherches en Informatique Médicale (SERIM). This study was partly supported by grants from the CHU de Lille.

1 Mayeux R, Stern Y, Rosen J, Leventhal J. Depression, intellectual impairment and Parkinson's disease. Neurology 1981;31:645-50.

2 Stern Y, Mayeux R. Intellectual impairment in Parkinson's disease. Adv Neurol 1986;45:405-8.

3 Ransmayr G, Poewe W, Ploerer S, Birbamer G, Gerstenbrand F. Psychometric findings in clinical subtypes of Parkinson's disease. Adv Neurol 1986;45: 409-11.

4 Pillon B, Dubois B, Bonnet AM, et al. Cognitive slowing in Parkinson's disease fails to respond to levodopa treatParkinson's disease fails to respond to levodopa trea
ment: the 15-objects test. Neurology 1989;39:762-8.

5 Sagar HJ, Sullivan EV, Gabrieli JDE, Corkin S, Growdon JH. Temporal ordering and short-term memory deficits JH. Temporal ordering and short-term memory

6 Lees AJ. The neurobehavioral abnormalities in Parkinson's disease and their relationship to psychomotor retardation and obsessional compulsive disorders. Behav Neurol 1989;2:1-11

7 Brown RG, Marsden CD. Cognitive function in Parkinson's disease: from description to theory. TINS 1990;13:21-9.

8 Mortimer JA, Pirozzolo FJ, Hansch EC, Webster DD. Relationship of motor symptoms to intellectual deficits in Parkinson's disease. Neurology 1982;32:133-7.

9 Cooper JA, Sagar HJ, Jordan N, Harvey NS, Sullivan EV. Cognitive impairment in early untreated Parkinson's disease and its relationship to motor disability. Brain disease and its relation

10 Pillon B, Dubois B, Cusimano G, Bonnet AM, Lhermitte F, Agid Y. Does cognitive impairment in Parkinson's F, Agid Y. Does cognitive impairment in Parkinson's disease result from non-dopaminergic
Neurosurg Psychiatry 1989;52:201-6.

11 Portin R, Rinne UK. Predictive factors for cognitive deterioration and dementia in Parkinson's disease. Adv Neurol 1986;45:413-6.

12 Lhermitte F, Agid Y, Signoret JL. Onset and end-of-dose levodopa induced dyskinesias. Arch Neurol 1978; 35:261-3.

13 Esteguy M, Bonnet AM, Kefalos J, Lhermitte F, Agid Y. Le test à la L-Dopa dans la maladie de Parkinson. Rev Neurol 1985;141:413-5.

14 Marsden CD, Parkes JD, Quinn N. Fluctuations of disability in Parkinson's disease clinical aspects. In: Marsden CD, Fahn S, eds. Mov Disord. London: Butterworth Scientific, 1982;96-122.

15 Lhermitte F, Agid Y, Feuerstein C, et al. Mouvements anormaux provoqués par la L-Dopa dans la maladie de anormaux provoques par la L-Dopa dans la maladie de
Parkinson: corrélation avec les concentrations plasmaParkinson: corrélation avec les concentrations plasma-
tiques de DOPA et de O-Méthyl-DOPA. Rev Neurol tiques de DOPA

16 Jankovic J. Parkinsonism-plus syndromes. Mov Disord 1989;4(suppl 1):95-119.

17 Lees AJ. Parkinson's disease and dementia. Lancet $1985 ; 1: 43-4$.
18 Rajput $\mathrm{AH}$, Offord $\mathrm{K}$, Beard $\mathrm{CM}$, Kurland LT Epidemiological survey of dementia in parkinsonism and control population. Adv Neurol 1984;40*229-34

19 Brown RG, Marsden CD. "Subcortical dementia": the neuropsychological evidence. Neurositence 1988;25 363-87

20 De la Monte SM, Wells SE, Hedley-White T, Growdon JH. Neuropathological distinction between Parkinson's dementia and Parkinson's plus Alzheimer's disease. Ann Neurol 1989;26:309 20.

21 Wechsler D, Stone CP. Wechsler memory scale manual. New York. NY: Psychological Corp, 1973.

22 Nelson HE. A modified card sorting test sensitive to frontal lobe defects. Cortex 1976;12:313-24.

23 Hughes AJ, Daniel SE, Kilford L, Lees AJ. Accuracy of clinical diagnosis of idiopathic Parkinson's disease: a clinico-pathological study of 100 cases. $f$ Neurol Neurosurg Psychiatry 1992;55:181 4 .

24 American Psychiatric Association, Committee on Nomenclature and Statistics. Diagnostic and statistical manual of mental disorders, revised third edition. Washington, DC: American Psychiatric Association, 1987.

25 Fahn S, Elton RL and members of the UPDRS Development Committee. Unified Parkinson's disease rating scale. In: Fahn S, Marsden CD, Calne D, Goldstein M, eds. Recent developments in Parkinson's disease. New Jersey: Macmillan Healthcare Information, ease. New Jersey:

26 Schwab RS, England AC. Projection technique for evaluating in Parkinson's disease. In: Gillingham FJ, Donaldson IML, eds. Third symposium on Parkinson's
disease. Livingstone, Edinburgh: Eyre and Spottiswoode, 1969:152-7.

27 Montgomery SA, Asberg M. A new depression scale designed to be sensitive to change. $B r \mathcal{F}$ Psychiatry 1979;134:382-9.

28 Caparros-Lefebvre D, Blond S, Pécheux N, Pasquier F, Petit $H$. Evaluation neuropsychologique avant et après stimulation thalamique chez 9 parkinsoniens. Rev Neurol 1992;148:117-22.

29 SAS Institute Inc. SAS STAT user's guide. 4th ed. Cary, NC: SAS Institute, 1989

30 Dubois B, Boller F, Pillon B, Agid Y. Cognitive deficits in Parkinson's disease. In: Boller F, Grafman J, eds. Handbook of neuropsychology. Amsterdam: Elsevier 1991;5:195-240.

31 Growdon JH, Corkin S. Cognitive impairments in Parkinson's disease. Adv Neurol 1986;45:383-92.

32 Dubois B, Pillon B, Sternic N, Lhermitte F, Agid Y. Ageinduced cognitive disturbances in Parkinson's disease. Neurology 1990;40:38-41.

33 Hietanen $M$, Teräväinen $H$. The effect of age of disease onset on neuropsychological performance in Parkinson's disease. $\mathcal{F}$ Neurol Neurosurg Psychiatry 1988; 51:244-9.

34 Martinez-Lage JM, Manubens JM, Lacruz F, et al. Risks factors for Alzheimer's disease: a case-control study in Pamplona. Neurology 1992;42(suppl 3): 141 .

35 Ruberg M, Agid Y. Dementia in Parkinson's disease. In Iversen LL, Iversen SD, Snyder SH, eds. Handbook of psychopharmacology. Vol 20: Psychopharmacology of the aging nervous system. New York: Plenum Press 1988 $157-206$.

36 Vermersch P, Delacourte A, Javoy-Agid F, Hauw JJ, Agid Y. Dementia in Parkinson's disease: biochemical evidence for cortical involvement using the immunodetection of abnormal tau proteins. Ann Neurol 1993:33: 445-50.

37 Marconi R, Caparros-Lefebvre D, Bonnet AM, Vidaillet $M$, Dubois B, Agid Y. Levodopa-induced dyskinesias in Parkinson's disease. Phenomenology and pathophysiology. Mov Disord 1994;9:2-12.

38 Caparros-Lefebvre D, Blond S, Vermersch P, Pécheux N, Guieu JD, Petit $H$. Chronic thalamic stimulation improves tremor and levodopa-induced dyskinesias in Parkinson's disease. $f$ Neurol Neurosurg Psychiatry 1993 56:268-73. 